\title{
On English Translation of Classical Chinese Poetry: A Perspective from Skopos Theory
}

\author{
Lei Gao \\ Foreign Language Department, Huaiyin Normal University, Huaian, Jiangsu, China. \\ E-mail: mrgaolei@163.com
}

\begin{abstract}
Classical Chinese poetry, an important part of Chinese culture, has always been a great task for translators, home and abroad. It is the foreign translators who, in the early $\mathbf{2 0}^{\text {th }}$ century, first translated the classical Chinese poetry into English. The Chinese scholars began to do the translation in the seventies of the $\mathbf{2 0}^{\text {th }}$ century. From the existent translations, foreign or Chinese, we can find that most translators had their clear purposes when translating. These purposes of translation influenced their choice of translation skills when dealing with the content and form of the poetry.
\end{abstract}

Index Terms - Classical Chinese poetry, skopos theory, poetic conception, image

\section{INTRODUCTION}

Robert Frost remarked, "Poetry is what gets lost in translation", which implies that poetry is some intangible, ineffable thing, which although constructed in language cannot be transposed across languages. Many writers have struggled to define the difficulties of translating poetry. Shelly once declared that:

it were as wise to cast a violet into a crucible that you might discover the formal principle of its color and odor, as to seek to transfuse from one language into another the creations of a poet. The plant must spring again from its seed, or it will bear no flower----and this is the burthen of the curse of Babel. (S. Bassnett \& A. Lefevere 2001: 58)

From these descriptions, we know that the translation of poetry, especially the translation from classical Chinese poetry into the western languages, is a tricky task. It is the foreign scholars that first translated Chinese poetry into English, such as Ezra Pound, Arthur Waley, and etc. Chinese scholars actually began the systematic research and translation of Chinese poetry in the seventies of the $20^{\text {th }}$ century. With the increasing cross-cultural communication, the classical Chinese poetry has been pushed to the foreground of translation. By now, there have appeared many English translations of Chinese poetry. But how to evaluate these translations is a question.

In order to objectively evaluate these translations, we should take into consideration the trend of thought in the literature and art of the translators' times, and the translators' purposes on translation. To some extent, all the translations, which have realized their translators' purposes and imposed positive impact on the readers, should be regarded as a success. The successful translations, however, do not necessarily mean perfect. In this paper, I will mainly study what is deliberately reproduced by the translators.

\section{Main Features of Classical Chinese PoEtry}

\section{A. Rhythm and Rhyme}

The rhythm of classical Chinese poetry is usually presented by the four tunes of Chinese language. On most occasions, the rhythm is expressed by the caesura. As a matter of fact, we often divide a sentence or a clause into several meaningful units for transient stops. These transient stops constitute the caesura of the classical Chinese poems, which conveys the rhythm. The caesura of classical Chinese poetry is quite similar to the foot of the English poetry. The classical Chinese poems are mostly rhymed, which makes the poems beautiful in sound.

\section{B. Poetic Form}

It is well known that there are some stringent regulations upon the forms of the classical Chinese poems. After reading some poems, one can easily draw a conclusion that form is an important factor of the Chinese poetry. In China, it is often heard that it is not what to say, but how to say that makes a poem. Without appropriate forms, poets can not express their subtle thoughts accurately.

\section{Artistic Conception}

The poetic conception is often put much emphasis on, which contains the poets' own feelings. The unique perspective of observing things, the unique poetic feelings, and the unique character can form a unique poetic conception of a particular poet. The chrysanthemum in TAO Yuan-ming's (陶渊明 a great poet of the East Jin Dynasty) poems almost represents the poet's own character, so that we can not even mention chrysanthemum without thinking of 
TAO Yuan-ming. The same is true with LI Po (李白 a great poet of the Tang Dynasty) and LU You (陆游 a great poet of the Song Dynasty), who will remind us respectively of the moon and the plum. Like the classical Chinese painting, the classical poems aim at conveying individual-oriented poetic conceptions, so they do not necessarily imitate or describe the objective things accurately. This is an important artistic law of classical Chinese poetry.

\title{
D. Poetic Image
}

The flexible juxtaposition of images is another important artistic law. In this regard, the grammar of Chinese language offers the poets a convenient tool, so that they can juxtapose the images together without any conjunctions or prepositions. This can increase the density of images, making the poems multi-meaningful. As a result, the poems are very implicit, and consequently the translators will certainly have more freedom of imagination and recreation. The poetic images and poetic conceptions are connected closely. It is mainly by these poetic images that poets express their poetic conceptions.

\section{E. Summary}

Facing the features of classical Chinese poetry, different translators always take different measures to cope with them, which can be reflected in their versions. The purpose of a translator plays an important role during the translating. They may choose to omit certain contents or forms of the original or deliberately antiquate their versions, and they may also attempt to over-translate, resulting in versions longer than the original.

\section{DifFERENT Translations OF LI PO's BALLAD OF A MERChant's WiFE}

\author{
长干行 \\ 妾发初覆额, 折花门前剧。 \\ 郎骑竹马来, 绕床弄青梅。 \\ 同居长干里, 两小无嫌猜。 \\ 十四为君妇, 差颜未尝开。 \\ 低头向暗壁, 千唤不一回。 \\ 十五始展眉, 愿同尘与灰。 \\ 常存抱柱信, 岂上望夫台。 \\ 十六君远行, 篗塘滟滪堆。 \\ 五月不可触, 猿声天上哀。 \\ 门前迟行迹, 一一生绿苔。 \\ 苔深不能扫, 落叶秋风早。 \\ 八月蝴蝶黄, 双飞西园草。 \\ 感此伤妾心, 坐愁红颜老。 \\ 早晚下三巴, 预将书报家。 \\ 相迎不道远, 直至长风沙!
}

Ezra Pound's translation:

The River- Merchant's Wife: A Letter

While my hair still cut straight across my forehead

I played about the front gate, pulling flowers.

You came by on bamboo stilts, playing horse,

You walked about my seat, playing with blue plums.

And we went on living in the village of Chokan:

Two small people, without dislike and suspicion.

At fourteen I married my Lord you.

I never laughed, being bashful.

Lowering my head, I looked at the wall.

Called to, a thousand times, I never looked back.

At fifteen I stopped scowling,

I desired my dust mingle with yours

Forever and forever and forever.

Why should I climb the look out?

At sixteen you departed,

You went into far ku-to-yen, by the river of swirling eddies,

And you have been gone five months.

The monkeys make sorrowful noise overhead.

You dragged your feet when you went out. 
By the gate now, the moss is grown, the different mosses,

Too deep to clear them away!

The leaves fall early this autumn, in wind,

The paired butterflies are already yellow with August

Over the grass in the west garden;

They hurt me. I grow older.

If you are coming down through the narrows of the river Kiang,

Please let me know beforehand,

And I will come out to meet you

As far as cho-fu-sa.

WENG Xian-liang’s(翁显良) translation:

The Trader's Wife

My first coiffure - twin tassels with a fringe. My first bouquet - dewy buds gathered in the front garden. That very day you came galloping down the street on a hobbyhorse. We played in the courtyard, capering and pelting each other with green plums.

Lose neighbors from childhood, we grew closer with the years, our friendship never clouded by the least misunderstanding. At fourteen I became your bride. So bashful was I that I used to sit silent for hours, head bowed before the wall, and no amount of coaxing could make me turn around. At fifteen I blossomed out, radiant with new awakened love. We would be one even unto dust. Sooner die than break faith, you declared. What would life be without you? It was impossible to contemplate.

But at sixteen I had to let you depart for the hinterland; such is the lot of a trader's wife. Up river you sailed in the teeth of the midsummer flood, past jagged rocks more dangerous for being sunken, through dismal gorges filled with the wails of apes on high.

The footprints you left behind are now overgrown with moss, so thick as to defy the broom. I feel the chill breath of autumn; I see the leaves wither and fall. But in my garden there are still patches of green with golden butterflies fluttering about — in pairs. The sight touches me to the quick. Youth and beauty can not endure. Why are you so long in returning? Delay no more, and do not forget to send word ahead. I will go to meet you halfway, however far that may be.

XU Yuan-Chong's(许沸冲) translation:

Ballad of A Merchant's Wife

My forehead covered by my hair cut straight,

I played with flowers pluck'd before the gate.

On a hobby-horse you came on the scene,

Around the well we played with plums still green.

We lived, close neighbors on Riverside lane.

Carefree and innocent, we children twain.

I was fourteen when I became your young bride,

I'd often turn my bashful face aside,

Hanging my head, I'd look towards the wall,

A thousand times I'd not answer your call.

I was fifteen when I composed my brows,

To mix my dust with yours were my dear vows.

Rather than break faith, you declared you'd die.

Who knew I'd live alone in a tower high?

I was sixteen when you went far away,

Passing Three Canyons studded with rocks gray,

Where ships were wrecked when spring flood ran high,

Where gibbons' wails seemed coming from the sky.

Green moss now overgrows before our door,

Your footprints, hidden, can be seen no more.

Moss can't be swept away: so thick it grows,

And leaves fall early when the west wind blows.

The yellow butterflies in autumn pass

Two by two o'er our western-garden grass.

This sight would break my heart, and I'm afraid,

Sitting alone, my rosy cheeks would fade.

Sooner or later, you'll leave the Western Land.

Do not forget to let me know beforehand. 
I'll walk to meet you and not call it far

To go to Long Wind Sands or where you are.

From the above translations, we can find that Ezra Pound wants to reproduce the forms of images. WENG Xian-liang wants to preserve the poetic conception of the original. XU Yuan-chong tries to reproduce both the original content and form. For example: the first four lines

妾发初覆额, 折花门前剧。

郎骑竹马来, 绕床弄青梅。

is translated into:

While my hair still cut straight across my forehead

I played about the front gate, pulling flowers.

You came by on bamboo stilts, playing horse,

You walked about my seat, playing with blue plums. (by Ezra Pound)

My first coiffure - twin tassels with a fringe. My first bouquet - dewy buds gathered in the front garden. That very day you came galloping down the street on a hobbyhorse. We played in the courtyard, capering and pelting each other with green plums. (by WENG Xian-liang)

My forehead covered by my hair cut straight,

I played with flowers pluck'd before the gate.

On a hobby-horse you came on the scene,

Around the well we played with plums still green. (by XU Yuan-chong)

Pound translated the original poem with a poetic form, concise and vivid, trying to preserve the forms of the images, for instance: “竹马” and “青梅” were literally converted into "bamboo stilts” and "blue plums”; WENG Xian-liang changed the poem into prose, getting the artistic conceptions well reproduced at the expense of the original artistic form. “花” was explained as “my first bouquet—dewy buds”. “来” was translated into “came galloping down the street”. “弄 青梅” was converted into "capering and pelting each other with green plums"; XU Yuan-chong translated the verse with a kind of typical poetic form, trying to reproduce the rich content and beautiful form of original poem. “花” was translated directly into “flower”. “竹马” was liberally converted into “hobby-horse”. “青梅” was literally translated into "plums green". Besides the beauties of sense and form, XU Yuan-chong's translation is also beautiful in sound, as we can find that there is an iambic pentameter in each line, and the poem is rhymed with a pattern of "aabb". In a word, no matter what translation method they take, the translators should be able to justify their choice of a particular purpose in a given translational situation. Nord said that:

This rule is intended to solve the eternal dilemma of free vs. faithful translation, dynamic vs. formal equivalence, good interpreter vs. slavish translators, and so on. It means that the purpose of a particular translation task may require a "free" or a "faithful "translation, or anything between these two extremes, depending on the purpose for which the translation is needed. (Christiane Nord 2001: 291)

To uphold certain purposes of a translator, of course, does not necessarily mean to degrade other translators' purposes. In fact, different readers will always get different meanings from the same text. We might even say that a "text" is as many texts as there are receivers. Vermeer summed it up by saying that any text is just an "offer of information" from which each receiver selects the items they find interesting and important. (Christiane Nord 2001: 31)

\section{Purpose InVEstigation of The AbOVE Three Translators}

\section{A. Ezra Pound}

Ezra Loomis Pound (1885-1972) was born in Hailey, Idaho, but grew up and was educated mainly in Pennsylvania. In 1912 he launched the Imagist movement, advocating concreteness, economy, and free verse. These were reinforced by his work on Ernest Fenollosa's literal versions of classical Chinese poems, which he turned into the beautiful free-verse lyrics of Cathay. Fenollosa had argued that Chinese written characters were ideograms-compressed and abstracted visual metaphors. In this interplay of concrete signs, Pound saw the model for a new kind of poetry, dynamic and economical, which juxtaposed not only images but diverse "facts"-allusions, quotations, fragments of narrative.

Imagism was a spirit of revolt against Conventionalities rather than a goal set up as in itself a permanently lasting objective. According to Amy Lowell's article of "Tendencies in Modern Poetry", the major objectives of the movement were: (1) to use the language of common speech, but to employ always the exact words - not the nearly-exact; (2) to avoid all cliché expressions; (3) to create new rhythms as the expressions of a new mood; (4) to allow absolute freedom in the choice of subject; (5) to present an image (that is, to be concrete, firm, definite in their pictures-harsh in outline); (6) to strive always for concentration which, they were convinced, was the very essence of poetry; (7) to suggest rather than to offer complete statement.

Pound stressed the importance of the target language, and was concerned primarily with the translation of texts from earlier periods or from non-western cultures. In the translation of poetry, Ezra Pound suggested that three kinds of poetry that may be found in any literature. The first of these is "melopoeia" where words are surcharged with musical 
property that directs the shape of the meaning. This musical quality can be appreciated by "the foreigner with the sensitive ear", but cannot be translated "except perhaps by divine accident or even half a line at a time"; the second is "phanopoeia" which he regards as the easiest to translate, for this involves the creation of images in language. The images were, of course, central to Pound's poetics; his third category, "logopoeia", "the dance of the intellect among words" is deemed to be untranslatable, though it may be paraphrased. (Susan Bassnett \& André Lefevere 2001: 64)

From his The River-Merchant's Wife: A Letter, Ezra Pound did his utmost to reproduce the original images literally. He wanted to imitate the juxtaposition of images in the Chinese poetry, and he paid little heed to the rhymes. His translation emphasized the overall effect not the faithfulness to the original. So, in translating, he referred to the explanations of Fenollosa, and he was even unwilling to make clear the real meaning of every image. For instances: “郎 骑竹马来”is translated into “You came by on bamboo stilts, playing horse...”; “早晚下三巴” into “If you are coming down through the narrows of the river Kiang", which are just a kind of mistranslation in terms of meaning.

In fact, according to Pound's purpose, it is the juxtaposition of images, not the sense that he tries to reconstruct. As we know, his translations gave birth to the great movement in poetry in the U.S. and his Cathay was regarded as the most beautiful poems in the $20^{\text {th }}$ century. According to imagist theory, Pound argued that poems should be concrete and succinct, and poems should not be used to narrate or describe things. His translations are not strictly faithful to the original, but they can reproduce the poetic feelings, and his translations can meet the aesthetic demands of the readers of his times.

\section{B. XU Yuan-chong}

XU Yuan-chong was born at Nanchang, Jiangxi Province, China in 1921. A productive translator, he has published more than forty books, most of which have exerted a great influence upon readers, home and abroad. On the basis of his translation practice, XU Yuan-chong put forward his own translation theories, especially on the translation of poetry. In translating, he has a clear purpose - to reproduce the poetic beauties in sense, sound and form. He advocates that the versions of poems should combine visual and aural beauties together, and they should reproduce the fusion of pictorial composition and musical arrangement.

XU Yuan-chong argues that the classical Chinese poetry has its beauties in sense, sound and form, so translators should take into consideration these aspects. Therefore, he put forward his translation theory of "Three Beauties". According to him, the "beauty in sense" of translation can reproduce the deep structure of the poems. (XU Yuan-chong 1984: 64) The "Beauty in sound" can reconstruct a kind aural beauty by means of rhyme, alliteration, consonance, repetition and so on. (XU Yuan-chong 1984: 69) In translating poetry, in many cases, it is impossible to translate the sound-effects, and there is often a conflict between the expressive and aesthetic functions-the poles of ugly literal translation and beautiful free translation. The "sound" is regarded as an inseparable part of a poem, so XU Yuan-chong always does his best to reproduce the sound-effects in his translations. The "Beauty in Form" means the "best words in best order". In the book Ten Lectures on Literary Translation, LIU Zhong-de (刘重德) points out that:

poems call for the beauty in form, sound and meaning. A translator of them should not be satisfied with the mere conveying of the ideas in the original, but must strive for the reproduction of the original beauty. To achieve this, he ought to, first of all, retain the original meaning and artistic conception and secondly, do his best to make his translation bear a certain due form, rhythm, and rime when necessary. (LIU Zhong-de 1995: 129)

In the book of Art of Translation, XU Yuan-chong states that the most important task for a translator to do is to reproduce the beauty in sense. In order to reproduce the beauty in sense, he insists that a translator should adopt the translation methods of Specification (深化), Equalization (等化) and Generalization (浅化).

A good translator should know what to reproduce and how to reproduce. To reproduce the beauties in sense, sound and form, XU Yuan-chong put forward the methodology of Specification, Equalization and Generalization.

\section{WENG Xian-liang}

WENG Xian-liang (1924 - 1983) was born in Shunde (顺德), Guangdong Province, China. In the field of translation theory and practice, he had ever achieved a great success, for which he received high praise from scholars home and abroad. In the preface of An English Translation of Chinese Ancient Poems (1985), he made a statement like this:

Poems are written to express the poets' aspirations, but all that can show the aspirations are not poems. Poets embody their aspirations in the images. The verse of the poets should have rhyme and rhythm. In translating poetry, it is very difficult to reconstruct the original images, rhyme and rhythm. Both these two aspects have their free dimensions and restricted ones as well. As for the reconstruction of the images, the translators cannot betray the original sense, so they are not free in this regard. To reproduce the images, which is not just like copying the pictures, depends upon the spirit, not the form, only absorbing the essence of the original, so the translators are free in this aspect. As far as the rhyme and rhythm are concerned, the translators should reproduce them creatively and be free from the traditional requirements, as different languages have different patterns of rhyme and rhythm, therefore, it does not matter to make the translations rhymed or unrhymed, decomposed or not. Nevertheless, it is not so free for translators to concern themselves with the reconstruction of the length and stress of the syllables. If one adopts the free method, when unsuitable, he is, to some extent, too slack, and his work can not be called translation; if he does not employ the free method, when necessary, he is too conservative, and his translation will have no elegance. (WENG Xian-liang 1985: preface) 
From this statement, we can understand WENG Xian-liang's purpose on the translation of Chinese poetry and the translation method he likes to employ. As for WENG Xian-liang's translation method, QIU Ke-an (装克安) remarks:

WENG Xian-liang converted Chinese poems into English prose, focusing on the reproduction of the poetic feelings and conception. He did not rigidly adhere to the word-for-word translation, and paid no heed to the length and order of the sentences. He occasionally generalized the concrete nouns. The advantage of this kind of translation method is conducive to getting the poetic conceptions understood directly by the foreigners, without the interference of special Chinese things or allusions. (WENG Xian-liang 1985: 107)

In the article of "True Coloring and False Complexion-Random Remarks on English Translation of Chinese Poetry", WENG Xian-liang argues that we should preserve the special Chinese poetic feelings when translating classical Chinese poems. If we employ the occidentalizing method, the true color of the original poems will be lost completely, so this kind of translation is not a real translation. He also pointed out that to seek similarity in form would cause false complexion, but to seek spirit out of form could preserve true color.

Some critics argue that WENG Xian-liang's translations are too free. But as a matter of fact, to reproduce the meaning of images constitutes his purpose of translation. It is the spirit not the form that he pursued during the translation. He always tried his best to get the correct sense behind the images. In order to reproduce the sense of the images, he even took the method of explanation, translating poems into prose.

As for the translation of the images, some think we should preserve the forms while others do not think so. Eugene A. Nida says:

if a close, formal translation is likely to result in a misunderstanding, certain changes must be introduced into the text of the translation or the literal translation may be retained and footnote explaining the likely misunderstanding must be added. (Eugene A. Nida 2000:125).

\section{CONCLUSION}

A poem may have different translations, as different translators may have different purposes in translating, and each translation may be a good poem. A translator should be able to justify their choice of a particular purpose in a given translational situation. The purpose of a particular translation task may require different translation techniques. Any poem is just an offer of information from which each translator selects the items they find important. The art of poetry translation is an art of choice. A good translator should know what to choose, what to omit, and how to strike a balance between loss and gains.

In this paper, I mainly talk about Ezra Pound, WENG Xian-liang and XU Yuan-chong in terms of their respective purposes and their influence on the translation of classical Chinese poetry. Ezra Pound chose to reproduce the juxtaposition of images; WENG Xian-liang chose to reproduce the meaning of images; XU Yuan-chong chose to reproduce the poetic beauties in sense, sound and form. In order to realize these purposes, they adopted different translation methods. It is wise for us to learn from the various strong points of different translation methods. We should have a clear purpose in mind before we actually do the translating.

\section{REFERENCES}

[1] Bassnett, Susan \& André Lefevere. 2001. Constructing Cultures-Essays on Literary Translation. Shanghai: Shanghai Foreign Language Education Press.

[2] LIU Zhong-de. 1995. Ten Lectures on Literary Translation. Beijing: China Foreign Language Press.

[3] Nida, E, A. 2000. Language, Culture, and Translation. Shanghai: Shanghai Foreign Language Education Press.

[4] Nord, Christiane. 2001. Translating as a Purposeful Activity- Functionalist Approaches Explained. Shanghai: Shanghai Foreign Language Education Press.

[5] WENG Xian-liang. 1985. An English Translation of Chinese Ancient Poems. Beijing: Beijing Press.

[6] XU Yuan-chong. 1984. The Art of translation. Beijing: China Foreign Language Press. 